\title{
Quality of life from the perspectives of older people
}

\author{
ZAHAVA GABRIEL* and ANN BOWLING*
}

\begin{abstract}
This paper report results from a national survey of quality of life (QoL), based on 999 people aged 65 or more years living in private households in Britain. The study produced both qualitative and quantitative interview data. The 999 survey respondents were interviewed in their own homes with a semi-structured survey instrument, and 80 were followed-up in greater depth at one and two years after the baseline interview. The material from the in-depth interviews is presented here. The main QoL themes that emerged were: having good social relationships, help and support; living in a home and neighbourhood that is perceived to give pleasure, feels safe, is neighbourly and has access to local facilities and services including transport; engaging in hobbies and leisure activities (solo) as well as maintaining social activities and retaining a role in society; having a positive psychological outlook and acceptance of circumstances which cannot be changed; having good health and mobility; and having enough money to meet basic needs, to participate in society, to enjoy life and to retain one's independence and control over life. The results have implications for public policy, and supplement the growing body of knowledge on the composition and measurement of quality of life in older age.
\end{abstract}

$\boldsymbol{K E Y} \boldsymbol{W} O R D S$ - quality of life, ageing, older people.

\section{Introduction}

Previous research literature suggests that the quality of life (QoL) reflects both macro-societal and socio-demographic influences on people and the personal characteristics and concerns of individuals. It can be argued that within societies there is a common core of values, and that their presence or absence influences overall QoL. But as QoL is also subjective, it is equally dependent upon the interpretations and perceptions of the individual (Ziller i974). As such, the definition and measurement of quality of life should be grounded empirically in lay views, and should reflect individual subjectivity and variation in the concept, whilst at the same time

* Department of Primary Care and Population Sciences, University College London. 
taking account of wider social circumstances. The established models of quality of life are however rarely multi-level or multi-domain. They range from basic, objective and subjective needs-based approaches, often derived from Maslow's (1954) hierarchy of human needs, to classic models based on psychological wellbeing, happiness, morale and life satisfaction (Andrews 1986; Andrews and Withey 1976; Larson 1978), physical health and functioning (Bowling 200I), social expectations (Calman I983), and the individual's unique perceptions (O'Boyle i997). Social gerontologists also focus on the importance of social and personal resources, self-mastery or control over life, autonomy (freedom to determine one's own actions or behaviour) and independence (the ability to act on one's own or for oneself, without being controlled or dependent on anything or anyone else for one's functioning) (Baltes and Baltes 1990). Reflecting the increasing recognition of the multi-faceted nature of QoL, researchers now often develop models based on combinations of these domains, e.g. the World Health Organisation's WHOQOL Group (1993) model.

While social gerontologists in the United States have a long tradition of investigating life satisfaction, including correlates of 'the good life' and positive as well as negative aspects of ageing (see Andrews 1986), in Europe, a large body of social research was heavily influenced by the positivist perspective of functionalism which focused on dependency (Phillipson and Walker i986). In much of Europe this led to a negative focus on old age as an inevitable time of dependency, poverty, service need and declining physical and mental health. The care needs of dependent older people were emphasised at the expense of rehabilitation, prevention and curative treatment (Roos and Havens 199I). Research based on this model inevitably under-estimated the quality of life of older people.

The gradual realisation of the flaws in this focus has shifted the emphasis towards a more positive view of old age, as a natural component of the life span (O'Boyle i997) and one which can provide personal fulfilment. It has also promoted recognition of the importance of the individual's perceptions of their life quality (Bowling 1995 $a$, 1995 $b$, г996; Hickey et al. 1999). Because of the individual nature of quality of life, Joyce et al. (1999) argued that a theory of quality of life must integrate knowledge from other cognitive theories, for example memory and information processing, because changes in an organism reflect either or both immediate effects and storage processes. Recalled information is subject to modification by previously stored information and by other new and existing inputs, and thereby reconstructed when recalled to conscious attention. Thus any stimulus may modify the individual's construction of their quality of life at any of these levels. They argued that the links between the levels may be stable or unstable, healthy or pathological, and represent 
different 'depths' of quality of life, which may vary in their status as 'traits' or 'states'; and that health status may be a 'trait' and general quality of life measures may assess 'states', although such distinctions remain unclear and require further investigation.

While existing models of QoL in old age have drawn some support from research on older people's perceptions of QoL (Farquhar I995; Fry 2000; Bowling et al. 2002), very little research has tapped lay views. The implication is that most existing models of quality of life have not been based on older people's views and priorities, and thus have not been tested adequately for content validity. How people construct their quality of life at various levels also remains a neglected but increasingly important area for research and public policy, given the projected increase in the older population - to one billion worldwide aged 6o or more years by 2020 (World Health Organisation i999).

This paper reports selected results from a British national dataset on the quality of life: others have and are being published elsewhere (Bowling et al. 2002 ; Bowling et al., in press; Bowling and Gabriel, in press). The quantitative survey collected interview data from 999 people aged 65 or more years living in private households in England and Scotland. They were asked about the quality of their lives and how that quality could be improved. This paper concentrates on the findings from qualitative follow-up interviews with 80 of the 999 survey respondents.

\section{Aims and methods}

The overall aim of the study was to contribute to the development of a conceptual framework and body of knowledge on quality of life in old age based on older people's views. The method for the main study was a national interview survey, the Quality of Life Survey, which sought to include all respondents aged 65 or more years living at home in four quarterly Office for National Statistics (ONS) Omnibus Surveys in Britain during I999 and 2000. Of 1,299 eligible respondents sifted by ONS from the Omnibus Surveys, the overall response rate for the four Quality of Life Surveys was 77 per cent (999): I9 per cent refused to participate and four per cent were not contactable during the interview period. Full details of the method and sample have been published elsewhere (Bowling et al. 2002; Bowling et al., in press; Bowling and Gabriel, in press).

The follow-up in-depth interviews about quality of life were carried out I2 to I8 months later. The aim was to interview a broad cross-section of respondents to the survey to obtain a better understanding of people's 
interpretations of the quality of life. A purposive sample of ro6 people was constructed using seven quota matrices based on the survey respondents' socio-demographic characteristics, health status, quality of life ratings and region of residence. Of the Io6 who were approached, 80 were successfully interviewed (Io had moved and 16 refused).

The in-depth interviews employed semi-biographical interview techniques and aimed to enable themes to emerge from the respondents' own stories. The interviewer (ZG) asked respondents first to describe key events in their histories, including marriage, work and parenthood where experienced. This approach enabled people to talk about the quality of life in the context of their overall lives, and enhanced the researchers' understanding of people's perspectives on life. Using an interviewer's check list, the respondents were then asked successively what they thought of when they heard the words 'quality of life', to describe their quality of life, what gave their lives quality, what took quality away from their lives and how it could be improved, what would make it worse, and about any changes since the survey interview. The interviews lasted approximately $60 \mathrm{~min}-$ utes, and were audio-recorded, transcribed, categorised by ZG, checked by AB, and analysed using NU*DIST (version 5) (Nudist Software 1999). One year later, brief telephone interviews elicited changes in the lives of half of the follow-up respondents. Those who reported changes were subsequently re-interviewed to explore these further. The detailed coding frames for the in-depth interviews were developed after the authors had read all the scripts and was refined as coding took place. The thematic coding was carried out by ZG. Each coded script was then read independently by $\mathrm{AB}$ for consistency in coding, interpretation, missed themes and errors in coding. Both $\mathrm{ZG}$ and $\mathrm{AB}$ agreed the final codes used in each script.

\section{Results}

The in-depth follow-up sample purposively included 40 men and 40 women, and their ages ranged from 65 to over 80 years. One-half were married and the remainder were single, widowed, separated or divorced. Of the total, 36 had an income of less than $£ 6,240$ per annum. Twentyfive were categorised as having 'excellent' or 'good' functional ability (performance in everyday tasks and mobility), 43 as 'fair' and the remainder as 'poor'. Thirty-five rated their overall QoL as 'so good, it could not be better' or as 'very good', while 28 rated it as 'good', Io as 'alright' and the remainder said it was 'bad', 'very bad' or 'so bad, it could not be 
T A B L E I. Older people's definitions of the constituents of quality of life

\begin{tabular}{|c|c|c|c|c|c|c|}
\hline \multirow[b]{2}{*}{ Constituent } & \multicolumn{2}{|c|}{$\begin{array}{l}\text { Good things that } \\
\text { give life quality }\end{array}$} & \multicolumn{2}{|c|}{$\begin{array}{l}\text { Bad things that take } \\
\text { quality away from lives }\end{array}$} & \multicolumn{2}{|c|}{$\begin{array}{l}\text { Mentioned } \\
\text { good or bad }\end{array}$} \\
\hline & $\%$ & $\mathrm{~N}$ & $\%$ & $\mathrm{~N}$ & $\%$ & $\mathrm{~N}$ \\
\hline Social relationships & 96 & $(77)$ & 80 & $(64)$ & 99 & (79) \\
\hline Home and neighbourhood & 96 & $(77)$ & 84 & $(67)$ & IOO & (8o) \\
\hline Psychological wellbeing & $9^{6}$ & (77) & 63 & (5o) & 99 & $(79)$ \\
\hline Other activities done alone & 93 & $(74)$ & - & (o) & 93 & $(74)$ \\
\hline Health & 85 & $(68)$ & 83 & (66) & 99 & (79) \\
\hline Social roles and activities & 80 & $(64)$ & I & (I) & 80 & $(64)$ \\
\hline Financial circumstances & 73 & (58) & 53 & $(42)$ & $9^{\mathrm{I}}$ & (73) \\
\hline Independence & 69 & $(55)$ & 46 & $(37)$ & 84 & $(67)$ \\
\hline Other/miscellaneous & I8 & (I4) & I9 & (I5) & $3^{\mathrm{I}}$ & $(25)$ \\
\hline Society/politics & I & (I) & 43 & (34) & 43 & $(34)$ \\
\hline Number of respondents & & $(80)$ & & (80) & & $(80)$ \\
\hline
\end{tabular}

Source: Bowling et al. (in press). International Fournal of Aging and Human Development. Reproduced with permission of Baywood Publishing Company.

Notes: Includes heterogeneous subgroups: good only, bad only, good or bad themes mentioned (single counting only).

worse'. They lived in six widely spread geographical regions of England and Scotland.

\section{Social relationships with family, friends and neighbours}

This section presents examples of the overall QoL themes mentioned by the 80 respondents during the in-depth interviews. These provide insights into why the identified domains of QoL were important to them. ${ }^{1}$ Table I indicates that having good social resources was said to be part of having a good quality of life by almost all respondents. Regular face-to-face contact with families was important to having a good quality of life for 59 respondents. Fifty people said they had 'good relationships' with relatives (i.e. emotionally supportive and loving relationships). These types of relationships enabled the respondents to feel that others cared about them and would always be there for them if they had a problem. Some people, particularly those who were widowed, appreciated the company and emotional support provided by their children or other relatives. Some respondents simply enjoyed spending time with their families and seeing them living happy lives. Others spoke of the importance of having people nearby by that they 'knew' well and who, they felt, could call if they had a problem or needed help. One woman expressed these feelings clearly:

Respondent: I have a daughter who lives about Io minutes away ... so I see her frequently. So I have her to hand, as it were, absolutely. 
Interviewer: And do you think that affects your quality of life?

R: Oh yes, definitely. Definitely, yes. It's (short pause) you know, always somebody I can call on, if there's a necessity so to do ... I can call upon my daughter ... which I am sure enhances my quality of life, because I think ... friends are very good friends, but you can't call upon people unless you know them terribly well to take you to the nursing home, for a test. You know, those sorts of things, you really need family for that.

Thirty-six respondents said that their QoL was enhanced through contact with their grandchildren, because it gave them an emotional boost to spend time with children and teenagers. Respondents also enjoyed a reciprocal relationship with their grandchildren. They liked to give advice and spoil their grandchildren, while they gained pleasure from seeing them happy and feeling loved by them. Some respondents enjoyed holidays with their grandchildren and others liked to have them staying at their homes. Older people also appreciated the practical help that older grandchildren could provide. Thirty-seven people said they enjoyed seeing friends for company and the opportunity to do things with others (particularly if they were widowed). They also said that they appreciated the emotional support and close contact which good friends provided.

Not all relationships were said to be good; 23 respondents said that they worried about or felt responsible for members of their family, and this detracted from their quality of life. Worries included younger family members' finances, poor health and relationship problems, such as adult children's marital break-ups. Some respondents still felt responsible for their adult children as well as their grandchildren, and would either support them financially or look after the grandchildren. Some respondents also felt responsible for very elderly relatives. They spoke either of caring for ageing relatives in poor health or of having to cope with their deaths by taking on an organisational role, such as arranging funerals.

Eighteen people mentioned losses which took quality away from their lives, including missing friends who had died or moved away from the neighbourhood, while ro mentioned missing family members who had died. This was said to have a great effect on their QoL and many said that it led to loneliness. Respondents also missed spending time with their friends or relatives, speaking on the telephone with them and gaining advice from confidantes. Although respondents often took part in social activities, they tended not to see old age as a time for making new close friends, but rather only to gain acquaintances through such activities. For example, one man said:

I had a very good friend (GM) who ... died now eight or nine years ago, but we used to talk a lot over problems, but ... when I lost him, I lost ... my main 
supporter from that point of view, because if I wanted to have a chat about something what I wasn't sure about I'd go and see him, and he'd do the same to me, so it was always, it was a mutual thing, but ... that's the trouble, you lose your confidant, you know, somebody, confidants if you like, the older you get.

Fourteen people said that they did not see their family as much as they would like to and 16 spoke of their children and grandchildren being 'too busy' to see them. It appeared that this was sometimes used to help the respondents feel better about not seeing their children and grandchildren regularly. Underlying the value placed on social relationships was the prevention of loneliness through access to company and entertainment, the need for reciprocal emotional support, feeling cared for, maintaining confidence, having someone to talk to, to provide advice, to call on for everyday help and in emergencies.

\section{Home and neighbourhood}

Neighbourhood resources, or neighbourhood social capital, was also said to contribute to a good quality of life by almost all respondents. More precisely, 49 respondents indicated that having good relationships with their neighbours contributed to good QoL. In the place of having family living nearby, neighbours could provide security, including reassurance that there was always someone looking out for them and someone who would provide help if it was needed. Relationships with neighbours involving the exchange of practical help, such as lifts to the doctor and help with shopping, were also highly valued. Respondents also spoke positively about having an age-mix in the neighbourhood. Some respondents regarded neighbours as friends and spent a lot of time with them. Close relationships with neighbours are likely to be important for older people who are ill or who lack transport or the physical mobility required to visit friends living far away.

During their interviews, 33 respondents mentioned that enjoyment of the area in which they lived enhanced their QoL. They said they enjoyed pleasant views and areas in which to take 'nice walks' as well as the sense of belonging to a community. Good facilities and local services were also important (the following were mentioned: shops, markets, post-office, health services, street lighting, refuse collection, police, and local or mobile library). The importance of environmental QoL was clearly stated by one man:

It's a very nice neighbourhood. The field at the bottom of my garden is quite a large field and is unique. It's a war memorial field ... It commemorates the ... people who died in the war. As such it has closed due to foot-and-mouth. The location of this house, which is a little way out of $\mathrm{O}$, has respectable people 
around it. This is a relatively noise-free area. It's pleasant in terms of the countryside. $\mathrm{O}$ is an interesting city and it's got lots of good walks even with footand-mouth. So the quality of my life is enhanced by the location of my house.

Twenty-eight people also mentioned deriving pleasure from their own homes and stated that this contributed to their QoL. Some felt proud of having lived in their homes for many years and associated them with happy memories, for example bringing up their children. Good public transport was also said to contribute to the QoL of 3I respondents. They appreciated free bus-passes or discounted fares for older people, so that they could travel without worrying about being able to afford to reach certain places. Having comfortable buses with a drop-step, making it easier to get on and off, and a regular and reliable service were also important. The benefit of having free bus-passes in some areas, enabling people with little income to get out and about, was really valued.

Poor public transport was said to have a negative impact on the QoL of 26 respondents. Some of them said that it was more difficult to get out and about because of inadequate transport. Uncomfortable buses could be painful for respondents with joint or mobility problems. Similarly, walking to distant bus stops (particularly in cold and wet weather or on icy streets in the winter), and getting on and off the older style buses without dropsteps could be difficult for them. Financial constraints could also restrain people from using public transport. Even with discounted bus fares for retired people, some respondents said they could not afford the expensive fares for short distances. Respondents also expressed the feeling that after a difficult journey they were not relaxed and could not enjoy themselves.

Poor local services and facilities more generally were said by 2 I respondents to affect adversely their QoL. Some of them felt that they were not given enough information about the facilities and activities available for older people in their area. Others claimed that the provision of social activities for older people by the local council was inadequate. They wanted to see educational and exercise classes close enough for them to attend. Some also expressed concern over the lack of a local police presence, and I7 respondents said that they felt unsafe while many spoke positively about 'the past' when they felt safer. For respondents who were in poor health, the state of the roads in their local area was important, to prevent uncomfortable and painful journeys by bus and car. It can therefore be seen that underlying the value placed on home and neighbourhood were having good neighbours who could provide friendship, be alert for emergencies, provide help and support if frail or ill, and substitute for relatives. Also valued were having a pleasant environment to live in, a community spirit, and having good local facilities, leisure activities, feeling safe, and having accessible, affordable public transport. 


\section{Psychological wellbeing and outlook}

People's lives and actions are influenced by their mental outlook, attitudes and personality characteristics. Almost all respondents stated that their personalities and experiences contributed to their overall QoL. This often involved personal philosophies about life and the way in which events and circumstances were interpreted by them, e.g. with either an optimistic or a pessimistic perspective. Positive influences on QoL which were mentioned included having a positive attitude and being optimistic, rather than feeling sorry for themselves or worrying about life; and more particularly a content and/or even-tempered disposition (mentioned by 46 respondents) and an optimistic approach to life which included being able to look forward to things (I3 respondents). Others spoke about 'taking each day as it comes' and not worrying about what might happen in the future. Respondents also mentioned the importance of acceptance and 'making the best of things', i.e. making the best of what they have, rather than focusing on negative aspects of their lives. This attitude had sometimes developed from their upbringing and earlier experiences, as in a wartime childhood. One respondent expressed this phlegmatism well:

You've got to develop a reasonable philosophy, otherwise you're just going to be bitterly disappointed all the time, and that's part of life's training ... if you still think that the world owes you a living, and that everything is going to turn out right, then you're always going to be disappointed, if things go wrong ... they'll go wrong, so that's a good attitude to have. ... There's no need to get depressed about it, it's just a fact of life.

Coping strategies, in particular the acceptance of one's lot, were employed by $3^{8}$ respondents to help them to face the negative changes of ageing, including the loss of health and mobility, bereavement and other life events. One respondent put it like this:

I think acceptance ... I've found when I've had ... like when my first husband was killed in a road accident, and my second husband, he sat and died suddenly ... you've got to accept that these things have happened, and you've got to move on. I think so anyway ... I mean there's some people [who say] 'Oh, she'll never get over that'. Well you never do get over it but if you can accept it you can start taking the steps, you've got to ... life's got to go on, hasn't it? ... I think acceptance and contentment, they're the sort of things: that's my simple philosophy ... But I've lived by it ... and I've got where I am (laughs) ... but as I say ... if some pensioners had $£ 500$ a week they still wouldn't be satisfied, they'd want six [hundred], wouldn't they?

Thirty-two respondents spoke of making a conscious effort to keep busy in order to prevent despondency. They viewed a good QoL as an active and varied life. They wanted to continue to take on all that life offered them as 
much as they could, in spite of the negative changes they associated with older age, such as having less energy and poorer health. Respondents did not let themselves watch TV during the day, so that they did not waste whole days in front of the television. Others completed a daily crossword or memorised facts or poems in order to remain mentally active and prevent dementia. The most explicit expression of these ideas was from respondents who claimed that people make their own quality of life:

Quality of life is what you make it, you can't buy it, or inherit it, or anything like that, you know. So ... as I say, it's what you make it ... So I've ... enlarged the area that I can draw on for quality of life.

Quality of life is what you do yourself. You know, if you want to sit and watch television all day, well that's it, perhaps that's your equation of quality of life. ... Mine is to get out and about and do things for myself, or see things that I would like to see or haven't seen, you know. I don't expect to sit back and expect quality of life to come through the door.

Many people said that negative feelings detracted from their QoL, and 25 mentioned negative feelings about the future. Such fears were strongly linked to ageing and involved worries about losing health and/or independence. These fears were enhanced for some, as one woman said, by awareness of illness and death among ageing friends and relatives:

I mean I often think well, what is there to look forward to, in old age? ... It can be frightening if you think about it, you think of all these people and friends of course that have been ill, or are ill, or have died and you think, oh, is this what's going to happen to us ... the thing which would frighten me the most would be going in a home. ... I don't ever want to have to do that, having had ... relatives - my mother went in a home. ... I don't think their quality of life was very good ... mentally they were both extremely alert ... but their bodies were just dying. And it's awful to watch it and to see it happening, especially when they're very alert, you know, and their bodies just give in.

Ten respondents said that their QoL was negatively affected by the past or bad memories, and some felt that autobiographical events had shaped their current QoL. Eight respondents also reported periods of depression and/or were unhappy with their lives, which adversely affected their QoL. Most of the respondents with poor wellbeing reported that they had suffered from negative life events and circumstances, e.g. the deaths of partners, other family members and/or friends. Thus poor psychological wellbeing and outlook were sometimes associated with adverse life events, for example bereavements and memories of these, and fears of ageing, ill-health, dependency and the future. Conversely, respondents who expressed a good outlook on life and said that it contributed to a good QoL 
stressed the importance of being optimistic in life, looking forward to things, being thankful for (still) being alive, being content, trying to enjoy life, being open to new activities, keeping busy, accepting situations and moderating expectations. They also made downward social comparisons with those who were worse off than themselves to maintain positive wellbeing. Respondents with these perspectives tended to feel one made one's own (good) QoL.

\section{Social activities and hobbies (communal and solo)}

Respondents mentioned the importance of 'keeping busy' in relation to psychological wellbeing. This theme recurred when most of them raised the value of social activities to their QoL, including reciprocal activities such as voluntary work and helping other people (which also made them feel valued). Undertaking voluntary work was said to contribute to having a good QoL by i7 respondents, and some said voluntary work was a way of keeping busy and remaining active after retirement. Mrs A felt that voluntary work enabled her to remain involved in society to gain self-worth and feel needed:

I enjoy people very much and I think being able to mix and socialise, the church life to me is very important. ... I was secretary but I have given that up at the church. I am still in charge of the flowers. I think the quality of life is being involved and having a part to play. I think if you lose your role in life then you start getting depressed, I think it is very important to be needed for whatever reason, and ... kind of have self-worth or something and know that people think you are worthy.

Engaging in mentally stimulating activities was said to be important for the QoL by i7 respondents. Some perceived old age as a time for learning new skills, which they had not had the chance to learn previously. Attending educational classes, for example, enabled respondents to meet new people and was a regular forum for socialising as well as mental stimulation. Going on holiday or weekends away were also important for $3^{6}$ people who enjoyed seeing new places, getting some sun and relaxing. Thus, the pursuit of social activities was important to people for retaining an interest in life, keeping busy and active, and meeting other people. Some activities, including those done alone, were valued because they provided mental stimulation, which people saw as important for their mental health. Voluntary work was valued for its reciprocal nature, and people liked to feel both valued and that they were giving something back to society in their retirement. 


\section{Health}

Most older people said that having good health gave them a good QoL. Sometimes they related this to their expectations of poorer health in older age. Some referred to being able to do what they wanted because they had good health, and that there was no QoL without health. One expression on these lines was:

I think that number one is having good health ... because without that you are restricted. ... I mean the other things follow on, like being able to go to the gym which I have just done, swim, we play bridge a lot.

On similar lines, many reported that deteriorating health adversely affected their QoL, while 32 mentioned not being fit enough to do what they wanted to do and having to give up activities, including driving, because of their poor health. It was frequently said by the respondents that they coped with their (poor health) problems by accepting them. The poor health of close others was said by 2 I respondents to have had a marked impact on the QoL, and the elaborations included worry about a spouse's or other close relative's health, or the burden of providing care. In the follow-up interviews one year later, most respondents mentioned deteriorating health (their own or a close other's) as the QoL domain that had changed.

\section{Financial circumstances}

Many respondents associated a good quality of life with being financially secure or comfortable, although they were generally modest in their expectations. They often spoke about the importance of having enough money to pay bills, not having to worry about money, and knowing that enough money was available should an unexpected expense arise. Some said that they appreciated having enough money to do and buy what they required, e.g. to run the car, to pay bills and to have holidays, and not to have to 'worry' about money and bills. They also linked their finances to their ability to enjoy life, i.e. being able to afford to do the things they enjoyed doing. Some respondents associated enjoyment with quality of life whilst others stressed empowerment. Money was an instrument which enabled them to do the things they liked doing. Several respondents also mentioned feeling lucky about their financial situation, and favourably compared themselves to others perceived to have less money. Some people were upset that they could not afford to buy new furniture or decorate their homes. Others could not afford enough domestic help, which they said they needed because of their declining health and mobility. Mrs Q who lived in sheltered housing and was losing her mobility, was asked 
what she would do if her finances improved. She spoke of the way in which new furniture would help her retain independence:

I should buy myself one of those adjustable beds. And a chair that I could stand up (from) easily ... and I should have some cupboards, in my bedrooms ... that would make life easier. Well, I'm talking millionaire, now, I would like a bath that you could get into easier, and all things that ... I could be independent until ... the rest of my days.

Nine respondents living on a state pension felt that they could not afford to enjoy life. When one woman was asked what kind of things they would buy if they had more money, she replied:

Well, I'd have a holiday for a start ... a good thing would be to be able to go to the cinema, I can't remember the last time I went there ... or [the] theatre, or a train ride, or little things that needs money ... [You] can't do anything on $£ 53$ a week. It's not enough ... to really enjoy life. I mean it's enough to get through, but what can you do on $£ 53$ ? ... But you know, we all pull together, me and (inaudible) me husband ... we just get through ... but nothing spare. ... So, I mean that does affect your life. If you've got money you can move, can't you? Even if you're not very good on your legs you can order taxis like you did. ... You can't do that on what I get.

Thus money was important to the quality of life, not just to ensure that basic needs were met, but to enable people to participate in society, to enjoy themselves, and to free them from worry about paying bills, about not having enough money to meet emergencies, or how they would pay for needed practical help.

\section{Independence}

Over two-thirds of the respondents emphasised the importance of retaining independence for their quality of life, and 2 I said that being able to walk and having good mobility was important. They said that they wanted to avoid the boredom and monotony of a life confined indoors through immobility, and wanted to continue to be able to do things for themselves, such as shopping and household tasks. Avoidance of dependency on others was a commonly-held value. Retaining their mobility and independence was also said to be important because it enabled the respondents to get outdoors, to enjoy life, to meet other people and to avoid being dependent on others. Thirteen people also appreciated the greater independence from time constraints since retiring, and said that this contributed to a good QoL. Without the pressures of long working hours, commuting to work, or juggling family and work, these respondents felt they had more time to enjoy life, to see their family and friends, and to take up hobbies and new social activities. This also enabled them to lie in during the 
morning, to stay up late at night, to eat at more varied times, and to take more short breaks and holidays. Relief from the pressure from work deadlines after retirement was also valued:

Not feeling pressured is lovely, having been in the teaching profession. ... With so many deadlines and so many things to do and juggling all these balls and the pressure is different now, it's a more self-imposed pressure. I look back and I think, oh, how did I do all of that?

Thirteen people explained that having a car gave their lives quality, as it meant they did not have to rely on public transport or on lifts from other people, and they could be independent. Eleven people, who were unable to drive, or who did not have access to a car, felt that this detracted from their QoL by decreasing their independence. Some were reliant on public transport (commonly a poor or infrequent service), which prevented them from travelling, seeing people and doing things they would like to do. Some women expressed regret at not having learnt to drive, or were prevented from continuing to drive by poor health. In each case they became dependent on their husbands for lifts. Widowed women, whose deceased spouses had driven the car and were themselves unable to drive, missed going out in the car and pursuing the activities it enabled. One widow, who could not drive, pointed to the negative effect on her social activities of not being able to drive:

I used to play bridge, which I love, but unfortunately ... I can't go out at night, now, you see, because I haven't a car. ... That would improve my quality of life: to be able to play bridge again.

Six respondents reported that they lacked energy or were in poor health, which prevented them from being able to do things for themselves. Being unable to do the shopping or housework, or being unable to go out for a walk, led to feelings of frustration. Overall, therefore, the maintenance of independence was important to people. Respondents disliked being dependent on others for help, even for lifts. Independence was threatened by poor health and mobility, and by lack of access to transport. On the positive side, independence was enhanced in older age when people were freed from the constraints placed on them by ceasing work. Independence was enhanced if they had retained their health, had an adequate income, and had access to a car.

\section{Conclusions}

These findings on perceived QoL are unique in being based on older people's views. They demonstrate that the domains of the quality of life 
are inter-linked and interact. It should however be remembered that the study has been of people living at home. Those living in nursing homes, hospitals or residential care were excluded, and the factors in their QoL are likely to differ substantially and merit separate investigation (Clark and Bowling I989). Quality of life, then, for the respondents to this survey was built on a series of inter-related main themes. These reflected commonlyheld core values, while individuals also articulated sub-themes reflecting their particular lives. Greater recognition is needed in quality of life research that the influential domains and variables are not only people's own personal characteristics and circumstances, but also that there is a dynamic interplay between people and the surrounding social structures of a changing society.

The descriptions of quality of life which emerged from the in-depth interviews were consistent with the model which emerged from the analysis of the survey data (Bowling et al. 2002). The consistently emphasised central planks of quality of life were social relationships, home and neighbourhood social capital, psychological wellbeing and outlook, activities and hobbies (solo), health and functional ability, and social roles and activities. The lay models presented here also emphasised the importance of financial circumstances and independence, which need to be incorporated into a definition of the overall quality of life.

To achieve a better understanding of the quality of later life, it is important to move beyond health and functional status and their impact on life as a proxy concept and measure. A model of the quality of life and its associated measurement scales should be based on concepts derived from older people themselves. Thus quality of life can be said to be about having good social relationships, help and support; about living in a home and neighbourhood that gives pleasure and which feels safe, is neighbourly, and has access to local facilities and services including transport; about engaging in hobbies and leisure activities (solo) as well as maintaining social activities and retaining a role in society; about having a positive psychological outlook and acceptance of circumstances which cannot be changed; about having good health and mobility; and finally having enough money to meet basic needs and to enable people to participate in society and to enjoy life, and to retain one's independence and control over life.

\section{NOTES}

I A more detailed categorisation of the themes, with examples, is available from the authors. 


\section{References}

Andrews, F. M. (ed.) 1986. Research on the Quality of Life. Institute for Social Research, University of Michigan, Ann Arbor, Michigan.

Andrews, F. M. and Withey, S. B. 1976. Social Indicators of Well-being: Americans' Perceptions of Life Quality. Plenum, New York.

Baltes, P. B. and Baltes, M. M. (eds) i99o. Successful Aging: Perspectives from the Behavioral Sciences. Cambridge University Press, New York.

Bowling, A. I995 $a$. What things are important in people's lives? A survey of the public's judgements to inform scales of health related quality of life. Social Science and Medicine, го, $1447-62$.

Bowling, A. 1995 $b$. The most important things in life: comparisons between older and younger population age groups by gender. International fournal of Health Sciences, 6 , I69-75.

Bowling, A. 1996. The effects of illness on quality of life. Fournal of Epidemiology and Community Health, 50, I49-55.

Bowling, A. 2001. Measuring Disease: A Review of Disease Specific Quality of Life Measurement Scales, second edition. Open University Press, Buckingham.

Bowling, A., Bannister, D., Sutton, S., Evans, O. and Windsor, J. 2002. A multidimensional model of QoL in older age. Ageing and Mental Health, 6, 355-7I.

Bowling, A. and Gabriel, Z. 2004. An integrated model of quality of life. Social Indicators Research, 69, $\mathrm{I}-36$.

Bowling, A., Gabriel, Z., Dykes, J., Marriott-Dowding, L., Fleissig, A., Evans, O., Banister, D. and Sutton, S. 2003. Let's ask them: definitions of quality of life and its enhancement among people aged 65 and over. International Fournal of Aging and Human Development, 56, 269-306.

Calman, K. C. I983. Quality of life in cancer patients: a hypothesis. Fournal of Medical Ethics, 10, 124-7.

Clark, P. and Bowling, A. I989. Observational study of quality of life in NHS nursing homes and a long-stay ward for the elderly. Ageing $\mathfrak{E}$ Society, 9, I23-48.

Farquhar, M. i995. Elderly people's definitions of quality of life. Social Science and Medicine, 4I, I439-46.

Fry, P. S. 200o. Whose quality of life is it anyway? Why not ask seniors to tell us about it? International Journal of Aging and Human Development, 5o, $36 \mathrm{I}-83$.

Hickey, A., O’Boyle, C. A., McGee, H. M. and Joyce, C. R. B. I999. The schedule for the evaluation of individual quality of life. In Joyce, C. R. B., O'Boyle, C. A. and McGee, H. (eds), Individual Quality of Life: Approaches to Conceptualisation and Assessment. Harwood Academic, Amsterdam, II9-33.

Joyce, C. R. B., McGee, H. M. and O'Boyle, C. A. I999. Individual quality of life: review and outlook. In Joyce, C. R. B., O'Boyle, C. A. and McGee, H. (eds), Individual Quality of Life: Approaches to Conceptualisation and Assessment. Harwood Academic, Amsterdam, $2 \mathrm{I} 5^{-24}$.

Larson, R. 1978. Thirty years of research on the subjective well-being of older Americans. Fournal of Gerontology, 33, I09-25.

Maslow, A. I954. Motivation and Personality. Harper, New York.

Nudist Software 1999. Dublin, Computing services, University College Dublin.

O'Boyle, C. A. I997. Measuring the quality of later life. Philosophy Transactions of the Royal Society of London, 352, I87 -9 .

Phillipson, C. and Walker, A. (eds) 1986. Ageing and Social Policy. Gower, Aldershot, Hampshire.

Roos, N. P. and Havens, B. I991. Predictors of successful aging. American Fournal of Public Health, 8I, 63-8. 
World Health Organisation 1993. Measuring Quality of Life: The Development of the World Health Organisation Quality of Life Instrument (WHOQOL). WHO, Geneva.

World Health Organisation i999. Health Futures. WHO, Geneva. Available on-line at http://www.who.int/hpr/expo

Ziller, R. C. 1974. Self-other orientation and quality of life. Social Indicators Research, I, $3 \mathrm{OI}-27$.

Address for correspondence:

Accepted 23 September 2003

Professor Ann Bowling,

Department of Primary Care and Population Sciences,

University College London, Royal Free Campus, Rowland Hill Street, London $\mathrm{NW}_{3}{ }_{2} \mathrm{PF}$, UK.

e-mail: a.bowling@pcps.ucl.ac.uk 